\title{
The Drivers of Cat Bond Spread in the Primary Market
}

\author{
Massimo Mariani ${ }^{1}$, Paola Amoruso ${ }^{1}$, Raffaele Didonato ${ }^{1} \&$ Alessandra Caragnano $^{1}$ \\ ${ }^{1}$ Department of Management, LUM University, Italy \\ Correspondence: Massimo Mariani, Department of Management, LUM University, Italy. E-mail: \\ mariani@lum.it
}

Received: December 15, 2017

Accepted: January 10, $2018 \quad$ Online Published: January 15, 2018

doi:10.5539/ijbm.v13n2p65

URL: https://doi.org/10.5539/ijbm.v13n2p65

\begin{abstract}
The current paper presents an empirical analysis concerning the cat bond spread determinants at the time of issue, to evaluate potential drivers of catastrophe bond prices in the primary market. Starting from the framework description following the main branch of existing literature in this field, the statistical significance of various determinants on the pricing of cat bond is measured, paying attention to a factor representative of economic and financial circumstances and market conditions in general, consequently not associated with the catastrophe risk, namely Libor; it will be considered in order to verify the absence of influence of risk free rate on spread in the primary market. The results achieved provide insight in understanding variation of catastrophe risk prices, by taking into account term structure as well as external conditions, thus evaluating which potential spread determinants could help to improve the explanatory power of an econometric pricing model.
\end{abstract}

Keywords: Bond Pricing, Catastrophe bonds, financial markets

\section{Introduction}

The increased number of natural disasters has drawn attention to the need of new solutions in order to face economic losses caused by catastrophic events. Among them, catastrophe bonds are bonds emissions covering determined catastrophic events (such as earthquakes, hurricanes or floods) in order to allow for the transfer of risk and obligations for the reimbursement of economic losses caused by the aforementioned events from the insurer to the capital market through a Special Purpose Vehicle (SPV) (Braun, 2011). The cat bond is structured as a reinsurance contract between the sponsor (typically insurance and reinsurance companies, governments, and generally cat-exposed corporations) and a special purpose vehicle (SPV).

The coupon paid is generally greater than the traditional market instruments as a premium for the higher risk (Cummis, 2008). In fact cat bond coupons need to take into account both the interest rate on capital, and the catastrophe related insurance risk. Because of this, this financial product allows the sponsor to prevent illiquidity situations that might occur following natural disasters; on the other hand investors can achieve benefits in terms of portfolio diversification, due to a low correlation of this market segment with the traditional market. Typically these securities are characterised by an average duration of three years and they relate to specific triggers. (Kenneth \& Froot, 1999).

The current work has the aim of investigating the significance of various cat bond spread determinants, according to the route already marked out in existing literature. Studies have often investigated cat bond pricing and how it is affected by various factors, related to term structure of each emission. The innovative nature of the present work is to include in the analysis a variable representative of external conditions, in other words depending on economic and financial circumstances and generally on market conditions. The aim is to prove the low influence exerted by the traditional market on the cat bond segment in the primary market, according to what has already been demonstrated by existing studies for the secondary market. Empirically the contribution will be the introduction of Libor variable in the applied model.

The present work is organised as follows: the next section retraces the main findings of the leading studies concerning cat bond pricing, in both primary and secondary market. The analysis performed in the present work is described in the third part, with a focus on selected variables and applied methodology. In this paragraph three hypotheses are made explicit: the first one asserts the absence of influence exerted by Libor on cat bond spread at the time of issue. The second one concerns the possible lack of significance of size emission in the model while the third one regards the expected influence of rating on spread. The last part of the work describes all the achieved results, highlighting the innovative contribution to the existing literature in terms of significance taken 
by Libor with regards to cat bond spread in the primary market. This outcome was not initially foreseeable in the light of the proved lack of correlation between traditional market and cat bond segment in the secondary market.

\section{Literature Review}

In the present work a multifactor model is proposed in order to prove that several factors are relevant to the bond spread, considered as dependent variable, focusing the analysis on the primary market. In particular, the regression model will test the significance of various potential spread determinants, providing a multitude of descriptive statistics. The considered independent variables of the performed analysis are size, trigger type, rating, region, risks/perils covered, duration and Libor. This kind of investigation follows a branch of literature focused on observing significant paths in the pricing of these instruments, as they have the peculiarity of being affected from the one hand by the likelihood of the catastrophic event and on the other hand by market movements typical of bonds. In existing literature, cat bonds specific characteristics such as size, term and trigger type have been already investigated by several authors, including Dieckmann (2009), who focused his analysis on the secondary market, adapting to cat bond segment some hypotheses already tested in the corporate bond market by Edwards et al. (2007). In fact the latter focused the analysis on the corporate debt market, finding that larger issue volumes were associated to lower transaction costs and consequently highlighting, in this market segment, size significance. However, with reference to size, findings of existing literature in cat bond field have been contrasting; for instance, Papachristou (2009) didn't find any statistically significant relation between size of the deal and the risk premium in the primary market. Moreover, the influence of term structure on the interest rate was largely debated by Cox, Ingersoll and Ross (1985). Cummis and Weiss (2009) stated that investors demand to be compensated with higher spreads in cat bonds secondary market in the case of indemnity trigger, because of the longer post-event loss verification and the possibility of moral hazard by the sponsor. With regards to covered territory and reference peril, possible effects of these factors in the primary market have already been investigated by Lei et al. (2008), Bodoff and Gan (2009) and Papachristou (2009), and have been subsequently the subject of following studies (e.g., Galeotti et al.,2012). Moreover, it's common knowledge that yields for corporate and government bonds are related to rating classes (e.g., Elton et al., 2001). Consequently a similar relation can be associated to the spread of cat bond. According to Guertler (2014) fixed-income investors usually look at securities with the same rating as characterised by the same risks, and a similar effect could be attributed to cat bonds in the secondary market. Finally, Libor will be considered in order to verify the absence of influence of risk free rate on spread in the primary market, according to the findings of the secondary market, present in existing literature. In this regard it can be stated that the low correlation between catastrophe bond segment and traditional market has been widely proved, with reference to secondary market, confirming benefits associated with investors who operate in cat bond market (Braun, 2014). According to the data presented by Artemis, specifically the Swiss Re Global Cat Bond Total Return Index, which represents cat bonds sector, has increased by $50 \%$ between 2011 and 2016 .

Concerning the methodology and data used in existing literature, the first empirical study was conducted by Lane in 2000, who developed a power function with two parameters, particularly the probability of first loss and the conditional expected loss, to a one year cat bond sample.

As mentioned above, a more complete analysis was conducted by Lei et al. (2008), based on a linear model, which considered the probability of exhaustion and transaction specific characteristics such as maturity, issue size, trigger type, and rating. In this case the data set was increased and covered the period from 1997 to 2007. Lane and Mahul (2008) examined a sample of tranches over the same period, investigating the effect of the underlying peril and the reinsurance cycle. Dieckmann (2009) developed cross section analysis of 61 cat bonds before and after the occurrence of Hurricane Katrina in August 2005 to reveal significant spread drivers in the secondary market, as well as the influence of catastrophic events on the pricing relation. This last aspect was also investigated by Ahrens et al. (2009), who tested the model of Lane (2000) through a Bayesian estimation technique over the period between 2003 and 2008. Moreover Gatumel and Gu'egan (2009) investigated the behavior of secondary market spreads from 2004 to 2009. Papachristou (2009), focused the attention on the primary market, studying factors that influence the cat risk premium, developing a generalized additive model to 192 bonds issued between 2003 and 2008. Bodoff and Gan (2009) based the analysis on a sample of 115 transactions issued before 2008 to identify a pricing approach, including expected loss, covered territory, and reference peril. One of the most exhaustive secondary market investigations has been conducted by Guertler et al. (2014), who studied the impact of financial market turmoil and large natural disasters on cat bond spreads applying panel data methodology. In fact, the most complete dataset of cat bond issues has been taken into account by Braun in 2014; he examined the influence of different spread determinants in the primary market on a sample of 466 tranches, issued between June 1997 and December 2012, through a series of OLS regressions. 
Hence, his work included several important stages, since the inception of this market in the 1990s, the effects of Hurricane Katrina in 2005, and the global financial crisis of 2008.

Taking into account several variables already investigated by academics, the contribution of the present work in existing literature is to introduce an unprecedented set of explanatory variables including London Interbank Offered Rate (Libor), in order to evaluate the potential impact of short-term interest rates on cat bond spread and improving the explanatory power of the existing econometric models.

\section{Econometric Analysis of Cat Bond Spread in the Primary Market}

\subsection{Testable Hypotheses}

According to the typical structure of catastrophe bonds, which are floating-rate securities, investors are expected to be compensated with regular coupons, consisting of a variable interest rate (e.g., Libor or Euribor) plus a spread, which governs the price of cat bonds. In other words, cat bonds pay a risk free benchmark rate and on top of that an excess return for the risks taken by investors. In this regard, there are different ways of looking at the pricing of cat bond and, as stated above, one of the most common is to look at the coupon payment to the investors.

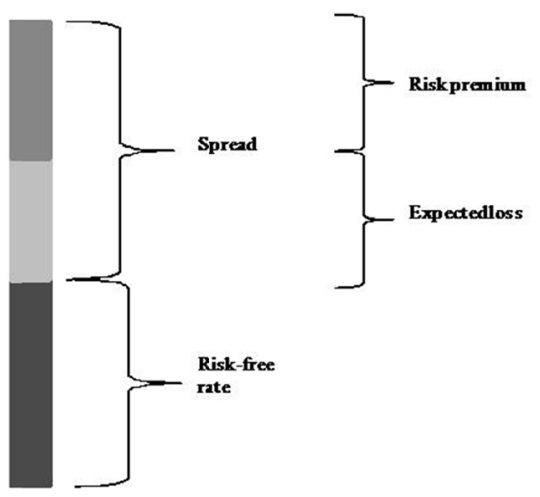

Figure 1. Breakdown of bond yield

Source: The Drivers of catastrophe Bond pricing, Partner Re, 2015.

Similar to other risky bonds, catastrophe bond spread is a function of modeled expected loss and risk premium. Modeled expected loss represents the average value of losses over a full range of scenarios. The risk premium indicates the required margin and these two factors are the drivers of catastrophe bond spread. Particularly, the risk premium isn't constant, since it is a function of peril zone and modeled expected loss.

The present work is focused on potential spread determinants that could help to improve the explanatory power of an econometric pricing model.

At first, we focused the attention on the relation between traditional market and cat bond segment, in the primary market, comparing possible findings with results already showed in existing literature and focused on the secondary market. In this regard, a variable representative of the traditional market has been selected; the chosen one is Libor, which is The London Interbank Offered Rate, defined as the average of interest rates estimated by each of the leading banks in London that it would be charged were it to borrow from other banks. According to the findings observed for the secondary market in previous studies, it is supposed that Libor will not show considerable influence on cat bond spread, since it is not indicative of cat risk; in particular the spread is the component of the coupon rate related to the event risk of a cat loss. Bodoff in 2009 defined the coupon as the sum of spread and Libor:

Total coupon rate $\%$ to investors $=$ Libor $\%+$ spread $\%$

Therefore, the spread is generally used to measure the price of risk transfer for cat bond issue. Since they are two separate components of coupon and in the light of absence of correlation noted in the secondary market, the first hypothesis is:

\section{Hp1: Libor does not affect cat bond spread.}

Moreover, in existing literature, bond specific characteristics such as size, term and trigger type were, as detailed above, already investigated by Dieckmann (2009) and Edwards et al. (2007); the latter focused the analysis on 
the corporate debt market, finding that larger issue volumes are associated with lower transaction costs. However, referring to bond prices, the influence of term structure on the interest rate was largely debated by Cox, Ingersoll and Ross (1985). Cummis and Weiss (2009) stated that investors demand to be compensated with higher spreads in cat bond secondary market in case of indemnity trigger, because of the longer post-event loss verification and the possibility of moral hazard by the sponsor. However, with particular reference to the size, findings of existing literature have been contrasting; for instance Papachristou in 2009 didn't find any statistically significant relation between size of the deal and the risk premium in cat bond primary market. Taking these considerations into account the second hypothesis is:

\section{Hp2: Size does not significantly affect the spread}

Finally, it is a matter of common knowledge, as evidenced by Elton in 2001, that yields for corporate and government bonds are affected by rating classes. A similar relation can be verified in the case cat bond spread and its rating. Lane and Mahul (2008) using a linear model analysis found that the risk prices are a function of different variables, including rating. Lei et al. (2008) similarly with a linear model investigated the influence of cat bonds detailed characteristics such as trigger type, size, maturity and rating in their study. Therefore, the third hypotheses can be explained as follows:

\section{Hp3: Rating has considerable influence on cat bond spread, since it completely reflects expected loss.}

\subsection{Methodology}

The actual lack of exhaustive research on cat bond prices is mainly due to the scarcity of available data. As already mentioned in literature review, various methodologies studying cat bond pricing have been applied over the years. Taking into account outcomes already achieved by scholars, the role of expected loss in cat bond pricing as well as the effectiveness of different functional forms for spread calculation models have been consistently verified.

Nevertheless, the debate about the determinants of the primary market spread is still ongoing. The present work has the aim of providing new empirical evidence from the primary market. The current contribution is based on an ordinary least squares (OLS) regression with heteroskedasticity on a data sample of cat bond issues in the primary market, with a reference period of 2011-2015. In particular, as explained in the following paragraph, an independent variable, representative of the cost of money at the time of issue, has been introduced and therefore, it is not connected to the specific risk associated to cat losses. Other independent variables have been selected in the light of experience of existing literature.

\subsection{Data Selection}

The main obstacle for empirical work on cat bonds is the scarcity of publicly available transaction data. The source used for the creation of our sample is The Artemis Deal Directory, which contains details about most of the catastrophe bonds and generally other Insurance Linked Securities transactions issued since this market segment began in the mid-nineties. The resulting data set is composed by 47 cat bond tranches between 2011-2015, whose spread at the time of issue, maturity, size (in USD), reference peril, region covered, trigger and rating (S\&P) are available. All selected tranches are USD denominated and they pay an excess return for the risks taken by investors on the top of an index for short-term interest rate, since cat bond are floating-rate securities.

In this regard the main obstacle has been the lack of accessible information for previous emissions, for the years before 2011, especially for size, rating, trigger and maturity; therefore, in order to obtain a consistent sample, tranches prior to this data have been excluded. Moreover we selected the monthly average of the 12-Month London Interbank Offered Rate (Libor) based on US dollar, published by the Federal Reserve Bank of St. Louis, for the month of issue of each considered tranche.

\subsection{Selected Variables}

Dependent variable:

Spread:

The dependent variable chosen for the performed analysis is the cat bond spread, widely used in existing literature; the spread of a catastrophe bond is intended to compensate investors for the insurance risk. Particularly, the spread represents the effective price of catastrophe risk transfer and it is in turn composed of modeled expected loss and risk premium. Thus, cat bond spread is similar to premium or rate on line in the traditional reinsurance market. Due to the data availability on the selected source, the effective spread value has been used.

Independent variables: 
The independent variables used in order to analyze different spread determinants are the following:

\section{Rating:}

The selected rating of our sample is provided by Standard \& Poor's and varies from B- to BBB+.

It is expected that rating will have a significant influence on spread, since it is essentially based on expected losses. In this regard it is appropriate to specify that usually the rating agencies base their rating on expected loss, but also on other factors which include legal risk, credit risk and others.

\section{Reference peril:}

The selected groups for reference peril are:

- Hurricane;

- Earthquake;

- Multiperil.

The latter includes storm surge, wind, tropical cyclone, earthquake, hurricane, severe thunderstorm, winter storm, wildfires, volcanic eruption and meteorite impact.

\section{Region covered:}

Three different macro areas have been identified: North America, Central America and Asia. In particular, Asia exclusively refers to Japan, because all cat bond tranches that affected Asian continent have focused on Japan.

\section{Size:}

Existing literature has often stated that the size of the transaction influences the spread, and this is an aspect that has been observed in markets for other assets. The rationale suggests that a larger size of deal may match a bigger number of investors and consequently a higher reward, as more investors require a greater price. However, no clear statistically significant relation between the size of the deal and the spread has been proved in the historical data.

\section{Maturity:}

For other classes of bonds the yield typically depends on the duration of the bond, as usually expressed by the yield curve, and the reasons can be different, such as future expectations about interest rates. Since the performed analysis refers to the primary market, maturity has been determined as the difference between the date of issue and the last scheduled payment.

\section{Trigger:}

Triggers are indices on the basis of which contractual obligations must be fulfilled and the cat bond capital is used to pay the sponsor of the transaction in case the covered catastrophic event takes place. There are different types of triggers:

- indemnity trigger based on payouts in function of the sponsor effective losses;

- index trigger based on an index representative of the accidents relatively to the whole sector;

- hybrid trigger which combines more types of trigger in a single bond;

- parametric trigger where the cat bond payout is triggered by certain physical measures of the catastrophic event (e.g. the wind speed or the magnitude and location of an earthquake);

- industry loss trigger where cat bond payoff is subject to the exceeding of a specified threshold by estimated industry-wide losses from an event.

A modelled-loss trigger is based on a model provided by catastrophe modelling firms (e.g. Applied Insurance Research Worldwide, EQECAT, or Risk Management Solutions). The index could be calculated by running the model on industry- wide exposures for a selected geographical area (Cummis, 2008).

In the current work, specific triggers used for the performed analysis are:

- Indemnity;

- Industry loss;

- Parametric;

- Modeled loss.

It is expected that they can have a different impact on the cat bond spread, since each trigger is based on different 
payoff mechanisms for investors.

Libor:

Libor (it has been used the monthly average of the 12- Month London Interbank Offered Rate -Libor- based on US dollar) is the benchmark for the risk free rate and it is a typical market variable; therefore it is not associated with the cat risk but it is just representative of the rate of return of an investment with no risk of financial loss, including only the cost of money without any links associated to the risk of catastrophic event. The Libor has been selected since all tranches of analyzed sample are USD denominated and most of these pay an excess return for the risk on the top of Libor (only a few selected tranches refer to US Treasury Money Market rate); in fact the only two Reference Rates for USD denominated cat bond emissions are USD Libor and US Treasury Money Market rate. Particularly it has been chosen the Libor since it is the most widespread in the investigated data set and it has been selected its specific value for the month of issue of each considered tranche.

Expected loss and Attachment probability:

The influence of expected loss in cat bond pricing has been consistently proved in existing literature; as specified above, expected loss is one of the two components of the spread and the use of a dependent variable which includes one of the independent variables is often avoided.

\subsection{Descriptive Statistics}

In this section, we provide a variety of descriptive statistics with regards to our sample. Table 1 contains the mean and standard deviation, as well as maximum and minimum values for some of the key characteristics of the data sample. The mean spread amounts to $6.1 \%$ in a range between $2.2 \%$ e $12.0 \%$. The mean maturity is almost three years and half, while the mean size is USD mln 207.40. The minimum size of the data sample is 50.00 USD mln, while the maximum is 500.00 USD mln. The longest maturity among selected tranches has duration of five years, while the shortest is of six months.

Table 1. Mean, Standard deviation, Minimum and Maximum for Size, Maturity and Spread

\begin{tabular}{ccccc}
\hline & Mean & SD & Min & Max \\
\hline SIZE (USD mln) & 207.40 & 108.12 & 50.00 & 500.00 \\
MATURITY (years) & 3.37 & 0.804 & 0.50 & 5.00 \\
SPREAD (\%) & 6.1 & 0.0267 & 2.2 & 12.0 \\
\hline
\end{tabular}

With reference to rating, the sample is distributed as follows:

Table 2. Data sample: Rating distribution

\begin{tabular}{cccccccc}
\hline & BB & BB- & BB + & B + & B & B- & BBB + \\
\hline $\begin{array}{c}\text { Rating } \\
\text { distribution }\end{array}$ & $28 \%$ & $21 \%$ & $19 \%$ & $17 \%$ & $9 \%$ & $4 \%$ & $2 \%$ \\
\hline
\end{tabular}

The major part of analyzed cat bonds is characterised by a "BB" and "BB-" rating; a significant proportion (19\%) is rated " $\mathrm{BB}+$ ".

As regards trigger type, the distribution of the data sample is the following:

Table 3. Data sample: Trigger distribution

\begin{tabular}{ccccc}
\hline & Indemnity & Industryloss & Modeledloss & Parametric \\
\hline Trigger distribution & $64 \%$ & $21 \%$ & $4 \%$ & $11 \%$ \\
\hline
\end{tabular}

The use of indemnity triggers in cat bond transactions has increased since 2012, according to Swiss Re's insurance-linked securities market report of 2012. Actually $64 \%$ of data sample is indemnity based; anyway industry loss and parametric indexes are fairly widespread, with respectively $21 \%$ and $11 \%$ of the sample. Non-indemnity indexes, particularly industry loss and parametric, are associated with basis risk, but they are characterized by lower cost and complexity to structure. 
With regard to reference peril, $62 \%$ of selected cat bonds transactions are referred to a set of natural hazards, particularly storm surge, wind, tropical cyclone, earthquake, hurricane, severe thunderstorm, winter storm, wildfires, volcanic eruption and meteorite impact.

Nevertheless, hurricane seems to be the most commonly covered peril, as it is often included in multiperil transactions.

Table 4. Data sample: Reference peril distribution

\begin{tabular}{cccc}
\hline & Hurricane & Earthquakes & Multiperil \\
\hline Reference peril distribution & $30 \%$ & $8 \%$ & $62 \%$ \\
\hline
\end{tabular}

In terms of the covered region, the great part of selected transactions is concentrated in different states of the U.S., identified in the sample as North America.

Table 5 shows correlations between selected variables, including expected loss and attachment probability, although they have been excluded for aforementioned reasons.

Table 5. Correlations between selected variables

\begin{tabular}{|c|c|c|c|c|c|c|c|}
\hline & Expected Loss & Attachment Probability & Size & Maturity & Libor Rate & Rating & Spread \\
\hline Expected Loss & 1.00 & & & & & & \\
\hline Attachment Probability & 0.93 & 1.00 & & & & & \\
\hline Size & -0.05 & -0.09 & 1.00 & & & & \\
\hline Maturity & -0.12 & -0.12 & -0.16 & 1.00 & & & \\
\hline Libor Rate & 0.17 & 0.09 & -0.44 & -0.17 & 1.00 & & \\
\hline Rating & -0.76 & -0.83 & -0.02 & 0.18 & 0.01 & 1.00 & \\
\hline Spread & 0.51 & 0.49 & -0.34 & -0.14 & 0.66 & 0.06 & 1.00 \\
\hline
\end{tabular}

Highest correlation values have been predictably recognized between expected loss (and also attachment probability) and spread as well as rating. Since these two variables show a high correlation with rating, in order to avoid multicollinearity, we shall not consider expected loss and attachment probability as independent variables. Libor and rating present no significant correlation between them; predictably there is a negative correlation between size and spread, as larger issues correspond to lower spreads, since they typically imply reduced transaction costs. Moreover a certain correlation between size and Libor has been observed; since Libor represents the cost of money, it seems reasonable to state that the lower cost of money corresponds to an increase in issue amount, probably because of the growing number of investors. Finally there is a surprisingly considerable correlation between spread and Libor.

\subsection{Regression Model}

Earlier literature has proved that a linear relationship is well-suited to explain primary market cat bond spreads (Galeotti et al., 2012). Thus, the developed inference statistical analysis will be based on OLS regression methodology. The performed model, which includes all regressors, can be formally described as follows:

$$
\begin{aligned}
& \text { Spread }_{i}=\beta_{1} \text { Size }_{i}+\beta_{2} \text { Maturity }_{i}+\beta_{3} \text { Parametric }_{i}+\beta_{4} \text { Indemnity }_{i}+\beta_{5}{\text { Industry } \text { Loss }_{i}}+
\end{aligned}
$$

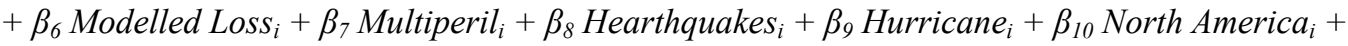

$$
\begin{aligned}
& +\beta_{11} \text { Asia }_{i}+\beta_{12} \text { Central America }_{i}+\beta_{13} \text { LIBOR }_{i}+\beta_{14} \text { Rating }_{i}+\varepsilon
\end{aligned}
$$

Where:

- $\quad \mathrm{i}$ is the considered emission;

- $\quad$ Spread is a quantitative variable indicating the spread rate of each issue;

- $\quad$ Size is a quantitative variable which indicates the size of the issue;

- Maturity is a discrete variable which indicates the maturity of the bond;

- $\quad$ Parametric, Indemnity, Industry Loss, Modelled Loss are dummy variables each indicating the trigger type of the bond; the generation of the dummies has been based upon the typical scheme taking value of 1 in presence of the attribute, 0 otherwise; 
- $\quad$ Multiperil, Earthquakes and Hurricane are dummy variables (generated as above) each indicating the peril covered by the bond;

- $\quad$ North America, Asia and Central America are dummy variables (generated as above) indicating the region covered by each bond;

- Libor is a quantitative variable which represents the value of the London Interbank Offered Rate at the time of issue;

- $\quad$ Rating is a discrete ordered variable on a scale from $1(\mathrm{~B}-)$ to $9(\mathrm{BBB}+)$ indicating the rating of the bond issue based on the S\&P Ratings;

- $\quad$ ci indicates the residuals.

Table 6. Results of Model (1)

\begin{tabular}{|c|c|c|c|c|c|}
\hline Independent variables & Estimate & Std. Error & t-value & p-value & Signif. codes \\
\hline Size & -0.002 & 0.002 & -0.893 & 0.3781 & \\
\hline Maturity & -0.174 & 0.309 & -0.561 & 0.5781 & \\
\hline Parametric & 1.760 & 2.011 & 0.875 & 0.3875 & \\
\hline Indemnity & 4.185 & 2.383 & 1.756 & 0.0878 & $*$ \\
\hline Industry Loss Index & 5.226 & 2.469 & 2.116 & 0.0415 & $* *$ \\
\hline Modelled Loss & 2.796 & 2.667 & 1.048 & 0.3016 & \\
\hline Multiperil & -0.312 & 0.895 & -0.349 & 0.7294 & \\
\hline Hurricane & -0.269 & 0.782 & -0.343 & 0.7333 & \\
\hline North America & -0.169 & 1.298 & -0.130 & 0.8971 & \\
\hline Asia & -1.823 & 1.718 & -1.061 & 0.2959 & \\
\hline Libor & 9.908 & 1.206 & 8.216 & $1.11 \mathrm{E}-09$ & $* * *$ \\
\hline Rating & -1.025 & 0.142 & -7.240 & $1.88 \mathrm{E}-08$ & $* * *$ \\
\hline \multicolumn{6}{|c|}{ Signif. codes: 0.01 '***’ 0.05 '**’ 0.1 '*, } \\
\hline Multiple R-squared & \multicolumn{5}{|l|}{0.9719} \\
\hline Adjusted R-squared & \multicolumn{5}{|l|}{0.9622} \\
\hline p-value: & \multicolumn{5}{|l|}{$<2.2 \mathrm{e}-16$} \\
\hline
\end{tabular}

The results for model (1) are shown in Table 6; as the p-value of the model is much lower than 0.01 , we reject with $99 \%$ confidence interval the null hypothesis that $\beta=0$. Hence there is a significant relationship between the variables used in the linear regression model and the dependent variable.

With reference to each single variable it is possible to observe how Libor rate at the moment of issue and the Rating of the bond have a major impact on the Spread, where their p-values achieve a significance level greater than $99 \%$.

Moreover the model shows a significant impact on the spread level given by the trigger, where in particular indemnity and industry loss appear to have a positive relationship. In other words the trigger type can considerably affect the cat bond coupon, with particular reference to Indemnity and Industry Loss Indexes, whose values appear to have a greater significance. It should be specified that coefficients for Earthquakes and Central America are not found because of singularities.

Ultimately, the model described in (1) explains more than the $95 \%$ of the variability of spread value, having a Multiple R-squared value greater than 0.97 and an Adjusted R-squared value of 0.9622.

All of these findings lead us to assume that the variability in the spread for cat bond issues in the primary market is mainly due to the analyzed factors.

\section{Discussion}

With reference to Hypothesis 1, the coefficient for Libor rate is highly significant, proving an impact on the spread in contrast to what expected in Hypothesis 1. 
In fact, a higher value of Libor is correlated to higher values of spreads as the (Beta13) factor has a non-zero positive value and shows high statistical significance.

In terms of causation, this suggests that when Libor increases, investors will expect a higher remuneration, and this will imply a growth in the spread, in order to make cat bond more attractive for investors.

Then, even if Libor is intended to compensate investors primarily for the holding of their money, independently from the insurance risk underlying the instruments, it holds a strong relationship with the spread, which should compensate the cat risk only. Consequently, for the primary market a substantial difference with the secondary market has been noted, in terms of influence of the traditional market.

Turning to Hypothesis 2, we find evidence that size does not affect spread significantly. Although in earlier research, for other assets, it has been observed that the size of the transaction has an effect on the premium; in the analyzed market segment size loses significance probably because there are other factors which better explain spread variation, exerting greater influence. This finding is consistent with what has been stressed by Papachristou in 2009.

Finally, we consider the results for Hypothesis 3, finding rating to be significant spread driver. In fact usually the rating agencies base their rating on several factors as legal risk, credit risk and others, including expected loss. As specified during the present work, the latter is a component of the spread, together with risk premium. Therefore it is expected that the rating has a significant influence on the spread and achieved outcomes actually prove our third hypothesis.

It should be noted that also trigger, particularly indemnity and industry loss, show a considerable influence on spread, although varying their effect since they provide for different remuneration arrangements. The lower transparency associated with these triggers could cause a major risk for investors, probably reflected in the spread increase.

\subsection{Model Validation}
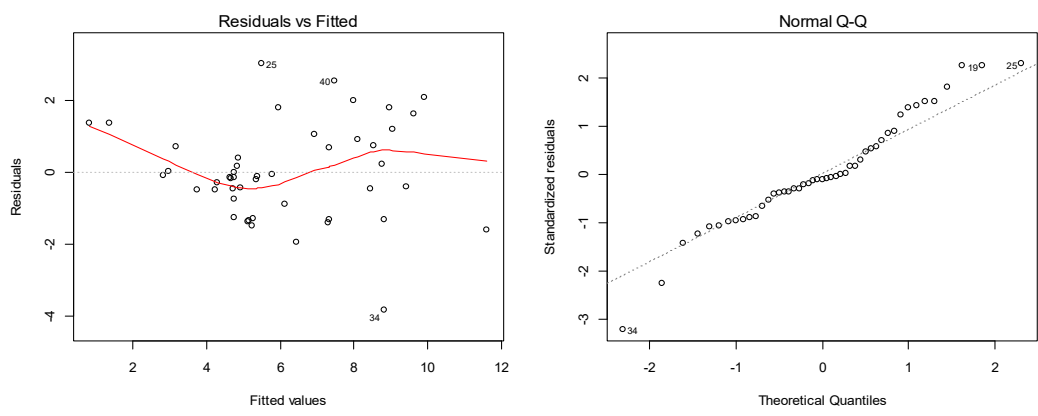

Figure 2. Student residuals of the model and the normal qq plots of the standardized residuals

If we turn to the residuals analysis, it provides further evidence of the model validity.

Figure 2 shows the student residuals of the model and the normal qq plots of the standardized residuals. The residuals, as it is highlighted in Figure 2, do not show any drift and apparently do not have any dependency.

With reference to the qq plot, the normality assumption appears to be weak at the tails; nevertheless the model appears to be robust.

As already specified in the previous paragraph, as the p-value of the model is much lower than 0.01 , we reject with $99 \%$ confidence interval the null hypothesis that $\beta=0$. Hence the linear regression model shows a significant relationship between the used variables and the dependent variable. Moreover the variability of spread value is effectively explained for more than the $95 \%$, since there is a Multiple R-squared value greater than 0.97 and an Adjusted R-squared value of 0.9622 . These two features prove the validity of the performer model.

Moreover, it is possible to assert the validity of the model with reference to the analysis of the residuals, which appears not to contain any predictive information and shows a random pattern.

\section{Conclusions}


The results achieved offer an additional point of consideration in understanding variation of catastrophe risk prices, by considering term structure as well as external conditions through a regression model, thus evaluating which potential spread determinants could help to improve the explanatory power of an econometric pricing model. Particularly, the attention has been focused on the relation between traditional market and cat bond segment at the time of issue and, in this regard, the variable representative of the traditional market, Libor, which is intended to compensate investors primarily for the holding of their money and consequently it is not related to cat risk, has showed a high significance, proving that if Libor rate increases, investors will expect a higher remuneration and this will imply a growth in the spread, in order to make cat bonds more attractive for investors. It can be stated that, even though there is a low correlation between cat bonds trend and the traditional market in the secondary market, as widely debated in existing literature, on the other hand cat bonds are also affected by the economic momentum at the time of issue.

Furthermore, evidence has been found that size doesn't significantly affect spread. Although in earlier research, for other assets, it has been observed that the size of the transaction influences the premium, in the analyzed market segment size loses significance probably because there are other factors which better explain spread variation, exerting greater influence.

Finally, rating has proven to be a significant spread driver. In fact, usually rating agencies base their rating on several factors as legal risk, credit risk and others, including expected loss. As previously specified, the latter is a component of the spread, together with risk premium. Therefore it is conceivable that the rating has a significant influence on the spread. It should be noted that also trigger, particularly indemnity and industry loss, shows a considerable influence on spread, although varying their effect since they provide for different remuneration arrangements. This result could be explained in the light of the lower transparency associated with these triggers, which causes a major risk for investors, probably reflected in the spread increase.

Although the performed analysis has provided interesting results, the only problem of the applied model is related to the limited data sample, due to the scarcity of publicly available transaction data. In this regard, it would be interesting in future researches to apply the same analysis on a broader sample, verifying if Libor keeps its significance unchanged. Anyway it is appropriate to specify that all researches of existing literature in this field, even the most detailed and expanded ones, refer to test samples otherwise limited compared to developed studies for other asset classes.

\section{References}

Ahrens, F., Fuess, R., \& Kestel, S. (2009). An Econometric Pricing Model for CAT Bonds and the Impact of the 2005 Hurricane Season. Working Paper, European Business School Research Paper Series 09-20.

Artemis. (2015). Discipline improves cat bond yields, market continues growth: John Seo.

Artemis. (2016). Swiss Re Global Cat Bond Index returns up in H1 2016.

Bodoff, N. M., \& Gan, Y. (2009), An Analysis of the Market Price of Cat Bonds, Casualty Actuarial Society E-Forum, Spring 2009, 1-26.

Braun, A. (2011). Pricing Catastrophe Swaps: A Contingent Claims Approach, Insurance: Mathematics and Economics, 49(3), 520-536, https://doi.org/10.1016/j.insmatheco.2011.08.003

Braun, A. (2014). Pricing in the Primary Market for Cat Bonds: New Empirical Evidence. Risk Management and Insurance, 116, 56-82.

Cox, J. C., Ingersoll Jr, J. E., \& Ross, S. A. (1985). A Theory of the Term Structure of Interest Rates, Econometrica, 53(2), 385-407. https://doi.org/10.2307/1911242

Cummins J. D. (2008). CAT Bonds and Other Risk-Linked Securities: State of the Market and Recent Developments, Risk Management and Insurance Review, 11, 23-47. https://doi.org/10.1111/j.1540-6296.2008.00127.x

Cummins, J. D., \& Weiss, M. A. (2009). Convergence of Insurance and Financial Markets: Hybrid and Securitized Risk-Transfer Solutions, Journal of Risk and Insurance, 76(3), 493-545. https://doi.org/10.1111/j.1539-6975.2009.01311.x

Dieckmann, S. (2008). By Force of Nature: Explaining the Yield Spread on Catastrophe Bonds. Working Paper, Philadelphia, Pennsylvania: Wharton School, University of Pennsylvania.

Edwards, A. K., Harris, L. E., \& Piwowar, M. S. (2007). Corporate bond market transaction costs and transparency, The Journal of Finance, 62(3), 1421-1454. https://doi.org/10.1111/j.1540-6261.2007.01240.x 
Elton, E. J., Gruber, M. J., Agrawal, D., \& Mann, C. (2001). Explaining the Rate Spread on Corporate Bonds, The Journal of Finance, 56(1), 247-277. https://doi.org/10.1111/0022-1082.00324

Galeotti, M., Guertler, M., \& Winkelvos, C. (2012). Accuracy of Premium Calculation Models for Cat Bonds An Empirical Analysis, Journal of Risk and Insurance, 80, 401-421. https://doi.org/10.1111/j.1539-6975.2012.01482.x

Gatumel, M., \& Gu'egan, D. (2009). Towards an Understanding Approach of the Insurance-Linked Securities Market. Working Paper, Paris, France: Panth'eon-Sorbonne, University of Paris.

Gennai, A. (2016, September 3). “Cat Bond” premiata la decorrelazione, Il sole 24 ore, 728, p.6.

Guertler, M., Hibbeln, M., \& Winkelvos, C. (2014). The Impact of the Financial Crisis and Natural Catastrophes on Cat Bonds, Journal of Risk and Insurance, 82(3), 579-612.

Kenneth, A., \& Froot, K. (1999). The financing of catastrophe risk. Chicago: University of Chicago Press.

Lane, M. N. (2000). Pricing Risk Transfer Transactions, ASTIN Bulletin: The Journal of the International Actuarial Association, 30(2), 259-293.

Lane, M. N., \& Mahul, O. (2008). Catastrophe Risk Pricing: An Empirical Analysis. Worl Bank Policy Research Working Paper, vol. 4765. Washington DC.

Lei, D. T., Wang, J.-H., \& Tzeng, L. Y. (2008). Explaining the Spread Premiums on Catastrophe Bonds. Working Paper, NTU International Conference on Finance, Taiwan.

Mariani, M., \& Amoruso, P. (2016). The Effectiveness of Catastrophe Bonds in Portfolio Diversification, International Journal of Economics and Financial Issues, 6(4), 1-8.

Papachristou, D. (2009). Statistical Analysis of the Spreads of Catastrophe Bonds at the Time of Issue. Paper presented at 39th ASTIN Colloquium, Helsinki, Finland.

\section{Copyrights}

Copyright for this article is retained by the author(s), with first publication rights granted to the journal.

This is an open-access article distributed under the terms and conditions of the Creative Commons Attribution license (http://creativecommons.org/licenses/by/4.0/). 